\title{
Progesterone decrease plasma membrane in human sperm with subnormal hypoosmotic swelling test scores
}

\author{
Sisca*,**, Luluk Yunaini***, and Dwi Ari Pujianto***
}

\section{ABSTRACT}

\section{BACKGROUND}

Progesterone (P4) is known as a female hormone affecting oocyte maturation and developing uterine wall. A proteomic study identified several receptors including $\mathrm{P} 4$ receptors on human sperm. The role of $\mathrm{P} 4$ in human sperm cells remains unknown as to whether $\mathrm{P} 4$ has non-genomic effects on human sperm. The present study aims to determine the effect of progesterone $(\mathrm{P} 4)$ on the hyperactivated motility and membrane integrity of human sperm cells.

\section{METHODS}

Semen from normal individuals was obtained from donors. The semen was washed by gradient density centrifugation. P4 was added to each semen sample to final concentrations of 0 (control), 250, 500, 750 and $1000 \mathrm{ng} / \mathrm{mL}$. After the sample treatment was completed, the sperm membrane integrity was assessed with the hypoosmotic swelling test (sodium citrate dihydrate and D-fructose) and the hyperactivated sperm motility parameter was determined with the Computer Assisted Sperm Analyzer [CASA] (Hamilton Thorne, IVOS II, USA). The percentage was then compared between the treatment groups and the control group. The percentage differences were analyzed with the Sigmastat version 2.0 statistical program.

\section{RESULTS}

Administration of P4 increased sperm hyperactivated motility when compared with the control group at a concentration of $500 \mathrm{ng} / \mathrm{mL}$, but the increase was statistically not signicant ( $\mathrm{p}>0.05)$. In contrast, $\mathrm{P} 4$ decreased sperm membrane integrity significantly $(p=0.042)$. And the mean of plasma membrane integrity in all groups was subnormal hypoosmotic swelling test score.

\section{CONCLUSION}

Progesterone administration tends to increase sperm hyperactivated motility. The integrity of plasma sperm membrane was affected by progesterone.

Keywords: Progesterone, fresh human sperm,membrane integrity, motility

\author{
*Department of Medical Biology, \\ Faculty of Medicine, \\ Universitas Trisakti, Jakarta \\ **Graduate Student for Biomedical \\ Science, Faculty of Medicine, \\ Universitas Indonesia, Jakarta \\ ***Department of Medical Biology, \\ Faculty of Medicine, \\ Universitas Indonesia, Jakarta
}

\section{Correspondence:}

Dwi Ari Pujianto, M.Biomed, PhD

Department of Medical Biology,

Faculty of Medicine,

Universitas Indonesia,

Jalan Salemba Raya No.6 Jakarta

Phone : +62 8111100944

Email : dwi.ari@ui.ac.id

Orcid ID :0000-0001-7546-3892

Date of first submission, September 4, 2018

Date of final revised submission, March 29, 2019

Date of acceptance, April 1, 2019

This open access article is distributed under a Creative Commons AttributionNon Commercial-Share Alike 4.0 International License

Cite this article as: Sisca, Yunaini L, Pujianto DA. Progesterone decrease plasma membrane in human sperm with subnormal hypoosmotic swelling test scores. Univ Med 2019;38:56-62. doi: 10.18051/UnivMed.2019.v38.56-62 


\section{INTRODUCTION}

Progesterone $(\mathrm{P} 4)$ is a steroid hormone which is released by the cumulus cells surrounding the ovum. ${ }^{(1)}$ Ovulation, implantation, and pregnancy are processes that involve P4. ${ }^{(2)}$ This steroid hormone causes the sperm cells to move towards the ovum then helps them to penetrate into the egg. ${ }^{(1)}$ Calcium influx and chloride efflux are induced by $\mathrm{P} 4$ as an essential way for successful fertilization, with effects that include sperm hyperactivation, acrosome reaction, and chemotaxis towards the ovum. ${ }^{(1,3)}$ The latter is described as irregular movement of the sperm head and flagellum to penetrate the ovum. One study reports that an insufficient amount of $\mathrm{P} 4$ is related to infertility, ${ }^{(3)}$ which may be due to the fact that $\mathrm{P} 4$ is a calcium mobilizing agent for sperm by generating $\mathrm{Ca}^{2+}$ release, causing a biphasic increase in $\mathrm{Ca}^{2+}$, and mediating P4induced $\mathrm{Ca}^{2+}$ influx in human sperm. Lack of $\mathrm{P} 4$ in sperm causes asthenozoospermia and is highly related to infertility problems. ${ }^{(3,4)}$

The human sperm proteome study by Baker et al. ${ }^{(5)}$ proved that sperm have progesterone receptors on their plasma membrane, ${ }^{(5)}$ and that there are several complex arrays of receptors including extragenomic $\mathrm{P} 4$ receptors.

The study by Sayme et al. ${ }^{(6)}$ showed that P4 increased hyperactivated motility in human sperm cryopreserved by slow freezing and vitrification, at $\mathrm{P} 4$ concentrations of $0,25,50 \mathrm{nM}$. The present study was different from that of Sayme et al. ${ }^{(6)}$ in that our study used fresh human sperm. The aim of the present study was to evaluate the effect of various $\mathrm{P} 4$ concentrations on hyperactivated motility and membrane integrity of fresh human sperm.

\section{METHODS}

\section{Research design}

This was an experimental in vitro study using normozoospermia donor semen at the Molecular Biology Laboratory, Universitas Indonesia, over a period of 1 year from March 2017 to March 2018.

\section{Semen samples}

This study used semen samples obtained from donors by masturbation after abstinence for 3-5 days. The samples were divided into five groups, comprising one group without $\mathrm{P} 4$ as control and four groups with different doses of P4 $(250,500,750,1000 \mathrm{ng} / \mathrm{mL})$. Each group contained a total of 10 million sperm. The experiment was repeated nine times using different semen donors.

\section{Sperm preparation and intervention}

Sperm was obtained from healthy normal donors. The sperm was washed out from the seminal plasma by putting $3 \mathrm{~mL}$ of the sperm sample on top of a Percoll gradient and centrifuging it at $1900 \mathrm{rpm}$ for 30 minutes. After centrifugation, the sperm was collected and separated from the supernatant. Then the sperm pellet was put into $1 \mathrm{~mL}$ of warm BiggersWhitten-Whittingham (BWW) medium. This medium consists of $0.21 \mathrm{~g}$ sodium hydrogen carbonate, $0.1 \mathrm{~g}$ D-glucose, $0.1 \mathrm{~g}$ polyvinyl alcohol (PVA), $0.05 \mathrm{ml}$ sodium pyruvate stock, $2 \mathrm{ml} \mathrm{4-}$ (2-hydroxyethyl)-1-piperazineethanesulfonic acid (HEPES), and $0.37 \mathrm{mLsodium}$ lactate. After that, the sample was checked to determine its normality. A volume of $95 \mu \mathrm{L}$ sperm was added to $5 \mu \mathrm{L}$ sperm diluting fluid, which is made from 2.5 $\mathrm{g}$ sodium hydrogen carbonate, $0.5 \mathrm{ml}$ formaldehyde, and $50 \mathrm{ml} \mathrm{H}_{2} \mathrm{O}$. A volume of 10 $\mu$ L diluted sample was added to a hemocytometer, left to stand for 2-3 minutes, then the number of sperm cells was counted in the five squares of the hemocytometer at $40 \mathrm{x}$ magnification. If the sample was normal, the sperm was incubated with progesterone (P4). Five hundred $\mu \mathrm{L}$ aliquots of the sperm sample, containing $10 \times 10^{6}$ sperm cells, were put into five Eppendorf tubes. Then $\mathrm{P} 4$ was added into those five tubes, at concentrations of $0,250,500,750$, and $1000 \mathrm{ng} / \mathrm{mL}$, respectively. After that, the samples were incubated at $37^{\circ} \mathrm{C}$ 
for $2 \mathrm{~h}$. before being subjected to membrane integrity and motility testing.

\section{Measurement of sperm hyperactivated motility}

The evaluation of sperm concentration and motility was performed using the Computer Assisted Sperm Analyzer [CASA] (Hamilton Thorne, IVOS II, USA). Sperm hyperactivated motility measures include total motility (TM) (\%), forward progressive motility (FPM) (\%), and velocity parameters such as curvilinear velocity (VCL) (m/sec), straight-line velocity (VSL, $\mu \mathrm{m} /$ $\mathrm{s})$, linearity of forward progression, which is the VSL to VCL ratio (linearity coefficient, LIN, \%), amplitude of sperm cell lateral deviation about its axis of progression or average path (amplitude of lateral head displacement, ALH, $\mu \mathrm{m}){ }^{.7)}$

\section{Measurement of sperm membrane integrity}

Sperm membrane integrity was assessed using the hypo-osmotic swelling (HOS) test. ${ }^{(8)}$ Ten microliters of sperm were mixed with 100 $\mu \mathrm{L}$ of HOS solution. Tail morphology was evaluated under a light microscope at 400x magnification. Sperm cells with bended/curly tails were considered as sperm with an intact plasma membrane, whereas those with straight tails were regarded as sperm with a disrupted plasma membrane. The percentages of intact and disrupted sperm plasma membranes were obtained by counting a total of 100 curly and straight-tailed sperm cells. According to WHO, the membrane integrity of normal sperm is more than or equal to $58 \%$ (5th centile, $95 \%$ CI $55-$ 63). ${ }^{(9)}$

\section{Statistical analysis}

Mean values of movement parameters and labeled sperm were compared between control and test samples by one way Anova. The post hoc differences between groups were analyzed by the Tukey HSD test. A value of $p<0.05$ was considered statistically significant.

\section{Ethical Clearance}

This research has been approved by the Health Research Ethics Committee, Faculty of Medicine, Universitas Indonesia, under No. 303/ UN2.F1/ETIK/III/2018.

\section{RESULTS}

The P4 dose-dependent effects on sperm motility and progressivity are illustrated in Table 1. In group I (control group), the percentage of motile sperm during the observation period was $30.14 \pm 16.25 \%$. The control group had a lower percentage of motile sperm compared to the $\mathrm{P} 4$ treatment groups. The highest percentage of motile sperm was in the $\mathrm{P} 4250 \mathrm{ng} / \mathrm{mL}$ group, amounting to $36.03 \pm 17.69 \%$. There were no significant differences between the control group and the $\mathrm{P} 4$ treatment groups $(\mathrm{p}>0.05)$.

In the control group, the percentage of progressive sperm during the observation period was $10.02 \pm 9.01 \%$. The control group showed a lower percentage of progressive sperm compared to that observed in the $\mathrm{P} 4$ treatment groups, but the result was not statistically significant. The highest percentage of progressive sperm was in the $\mathrm{P} 4500 \mathrm{ng} / \mathrm{mL}$ group, namely $15.46 \pm 15.27 \%$.

Table 1. The percentages of motile sperm and progressive movement parameter in the control group and after incubation with progesterone

\begin{tabular}{lcccccc}
\hline \multirow{2}{*}{ Parameter } & \multicolumn{5}{c}{ Progesterone concentration (ng/mL) } & p value \\
\cline { 2 - 7 } & I & II & III & IV & V & \\
\hline Motile (\%) & $30.14 \pm 16.25$ & $36.03 \pm 17.69$ & $35.32 \pm 23.95$ & $32.02 \pm 21.27$ & $33.57 \pm 6.88$ & 0.173 \\
Progressive (\%) & $10.02 \pm 9.01$ & $12.20 \pm 10.98$ & $15.46 \pm 15.27$ & $14.11 \pm 13.64$ & $13.20 \pm 9.79$ & 0.216 \\
\hline
\end{tabular}

I: control; II: incubation with progesterone $250 \mathrm{ng} / \mathrm{mL}$; III: incubation with progesterone $500 \mathrm{ng} / \mathrm{mL}$; IV: incubation with progesterone $750 \mathrm{ng} / \mathrm{mL}$; V: incubation with progesterone $1000 \mathrm{ng} / \mathrm{mL}$. Values are presented as mean $\pm \mathrm{SD}$ 
Table 2. Sperm motion parameter and membrane integrity in the control group and after incubation with progesterone

\begin{tabular}{lcccccc}
\hline \multirow{2}{*}{ Parameter } & \multicolumn{5}{c}{ Progesterone concentration (ng/mL) } & p value \\
\cline { 2 - 6 } & I & II & III & IV & V & \\
\hline VCL $(\mu \mathrm{m} / \mathrm{sec})$ & $52.13 \pm 12.12$ & $59.18 \pm 8.73$ & $61.03 \pm 15.81$ & $60.75 \pm 23.17$ & $62.26 \pm 9.59$ & 0.074 \\
LIN $(\%)$ & $40.10 \pm 8.06$ & $43.6 \pm 6.82$ & $43.49 \pm 6.41$ & $43.25 \pm 6.30$ & $42.22 \pm 5.12$ & 0.113 \\
ALH $(\mu \mathrm{m})$ & $3.00 \pm 0.82$ & $3.62 \pm 0.70$ & $3.49 \pm 0.85$ & $3.54 \pm 1.09$ & $3.63 \pm 0.84$ & 0.126 \\
Membrane & $43.00 \pm 1.15$ & $34.00 \pm 1.00$ & $37.00 \pm 3.00$ & $44.00 \pm 15.00$ & $49.00 \pm 16.00$ & 0.042 \\
Integrity $(\mu \mathrm{m} / \mathrm{sec})$ & & & & & & \\
\hline
\end{tabular}

I: control; II: incubation with progesterone $250 \mathrm{ng} / \mathrm{mL}$;III: incubation with progesterone $500 \mathrm{ng} / \mathrm{mL}$; IV: incubation with progesterone $750 \mathrm{ng} / \mathrm{mL}$; V: incubation with progesterone $1000 \mathrm{ng} / \mathrm{mL}$ Values are presented as mean $\pm \mathrm{SD} ; \mathrm{p}=$ significance level, $p<0.05$. VCL: curvilinear velocity; LIN: linearity coefficient; ALH: amplitude of head lateral displacement

After $2 \mathrm{~h}$ of $\mathrm{P} 4$ incubation, VCL in the control group $(52.13 \pm 12.12 \mu \mathrm{m} / \mathrm{sec})$ was observed to be lower compared with the P4 treatment groups $(59.18 \pm 8.73 \mu \mathrm{m} / \mathrm{sec}-62.26$ $\pm 9,59 \mu \mathrm{m} / \mathrm{sec})(\mathrm{p}=0.074)$, but this result was not statistically significant $(\mathrm{p}>0.05)$. The LIN in the control group $(40.10 \pm 8.06 \%)$ was lower than that in the $\mathrm{P} 4$ treatment groups $(>42 \%)$ $(p=0.113)$. The amplitude of the head lateral displacement in the control group (3.00 \pm 0.82 $\mu \mathrm{m})$ was lower than in the $\mathrm{P} 4$ treatment groups $(>3 \mu \mathrm{m})$. Furthermore, no statistical differences were found for ALH at any P4 dose (Table 1).

In all groups, the mean of the plasma membrane integrity had a subnormal hypoosmotic swelling test (HOST) scores $(<50 \%)$. P4 addition to sperm slightly decreased membrane integrity of the sperm cells in the P4 $250 \mathrm{ng} / \mathrm{mL}$ and $500 \mathrm{ng} / \mathrm{mL}$ groups but increased sperm membrane integrity in the $\mathrm{P} 4750 \mathrm{ng} / \mathrm{mL}$ and 1000 $\mathrm{ng} / \mathrm{mL}$ groups compared to untreated sperm $(p=0.042$; Table 2$)$, the increase being statistically significant. A posthoc Tukey test showed that the control group and $\mathrm{P} 4$ treatment grcups at doses of 250,500 , and $750 \mathrm{ng} / \mathrm{mL}$ differed significantly at $\mathrm{p}<0.05$, with overall mean differences of respectively $-3.03,-4.18$ and 2.71 ; the control group was not significantly different from the $\mathrm{P} 4$ $1000 \mathrm{ng} / \mathrm{mL}$ group (Table 3).

\section{DISCUSSION}

The P4 treatment samples had different motile sperm percentages even though all fulfilled normozoospermia criteria (motile sperm percentage $>32 \%) .{ }^{(10,11)}$ In contrast to progressive sperm percentages, the minimum semen criteria were achieved after P4 $500 \mathrm{ng} /$ $\mathrm{mL}$ treatment. This data indicates that $\mathrm{P} 4$ increases the percentage of progressive and motile sperm. Progesterone is a steroid hormone with a non-genomic action that causes increased intracellular $\mathrm{Ca}^{2+}$ to trigger sperm motility and hyperactivation, and acrosome reaction. ${ }^{(12)}$ Therefore it is expected that the addition of an optimum dose of P4 can exert potential effects on sperm motility.

The control group of this study showed the lowest hyperactivity of sperm compared with after P4 treatment. This is consistent with a previous study by Sumigama et al. ${ }^{(13)}$ who reported that fertilization increased when the sperm were exposed to a medium containing P4 compared to the control (BWW medium). This was because the administration of $\mathrm{P} 4$ stimulated an increased $\mathrm{Ca}^{2+}$ concentration in the sperm.

Table 3. Plasma sperm membrane integrity with Tukey HSD post-hoc comparison

\begin{tabular}{cccc}
\hline & $\begin{array}{c}\text { Treatment } \\
\text { groups }\end{array}$ & $\begin{array}{c}\text { Mean } \\
\text { Difference }\end{array}$ & p value \\
\hline I & II & -3.0333 & 0.015 \\
& III & -4.186 & 0.002 \\
& IV & 2.710 & 0.026 \\
& V & 0.930 & 0.392 \\
II & III & -1.153 & 0.293 \\
& IV & 5.743 & 0.000 \\
& V & 3.963 & 0.003 \\
III & IV & 6.896 & 0.000 \\
& V & 5.116 & 0.001 \\
IV & V & -1.780 & 0.017 \\
\hline
\end{tabular}

Note : mean difference is significant at the 0.05 level 
The elevation of intracellular $\mathrm{Ca}^{2+}$ from ionic influx and detachment from the intracellular reserve is very important in sperm function, resulting in changes in sperm motility and lipid membrane remodeling which causes the sperm to form bonds with the pellucid zone and induce acrosomal reactions. ${ }^{(4,14)}$ Curvilinear velocity, LIN and ALH are important indicators of hyperactivity for successful fertilization, so it can be concluded that $\mathrm{P} 4$ can be a mediator for in vitro fertilization. ${ }^{(15,16)}$

Based on Table 2, it can be seen that sperm membrane integrity has slightly decreased for 2 $\mathrm{h}$ incubation, based on WHO criteria (normal $\geq 58 \%$ ). To determine whether there was a significant difference in sperm membrane integrity in each P4 treatment group, statistical analysis was performed. Samples from two donors had different percentages between the control and experimental groups.

Lodi et al. ${ }^{(17)}$ demonstrated that there is a relationship between motility, viability and membrane integrity. However, this is not in accordance with our results. The study of Duru et al. ${ }^{(18)}$ revealed that $\mathrm{P} 4$ has no effect on the HOS test to improve sperm membrane integrity after postfreezing. This is also supported by research by Smith et al. ${ }^{(19)}$ showing that $\mathrm{P} 4$ can disrupt the integrity of the sperm membrane. Postthaw sperm cells are alive but have low membrane integrity.

The integrity of the sperm membrane is determined by several factors. Henning et al. ${ }^{(20)}$ reported that washing by density gradient centrifugation can cause sperm membrane integrity disruption due to the several stages of the washing process that can cause sperm cell membrane damage. Mohammadi and Mahdion ${ }^{(21)}$ stated that the sperm membrane is biochemically disrupted during the process of freezing and thawing.

In the present study, it appears that the P4 treatment has an important effect, but perhaps the study has an inadequate number of samples for this difference to be statistically significant. Another limitation is that semen donor current disease was underreported, which may have caused an underestimation of the true association. Our study was able to demonstrate that P4 in vitro increased the hyperactivated motility in sperm cells, and this can be used to improve the success rate of intra-uterine insemination. ${ }^{(22)} \mathrm{Next}$, a study on time-dependent P4 effects should be carried out to determine the time required for sperm incubation with $\mathrm{P} 4$.

\section{CONCLUSIONS}

The addition of progesterone in vitro tends to increase sperm motility, but the increase is statistically not significant. Plasma sperm membrane integrity decreasesd so that progesterone have an effect on sperm membrane integrity.

\section{CONFLICT OF INTEREST}

Competing interests: no relevant disclosures.

\section{FUNDING DISCLOSURE}

There is no financial conflict of interest to disclose.

\section{ACKNOWLEDGMENT}

This study was funded by competencebased cluster research grant 2010 from Universitas Indonesia. This study was funded by competence-based cluster research grant 2010 from Universitas Indonesia. This study was funded by Research Grant for Indexed International Publication For Student Final Assignment 2017 from The Research Council and Community Services of Universitas Indonesia.

\section{CONTRIBUTORS}

SS and DAP were responsible for managing research designs, collected 
manuscripts and funding. SS contributed to data acquisition and LY to data analysis. All authors have read and approved the final manuscript.

\section{REFERENCES}

1. Lishko PV, Botchkina IL, Kirichok Y. Progesterone activates the principal $\mathrm{Ca}^{2+}$ channel of human sperm. Nature 2011;471:387-91. doi: 10.1038/ nature09767.

2. Meharvan S, Chang S, Selena N. Non-genomic mechanisms of progesterone action in the brain. Front Neurosci 2013;7:159. doi: 10.3389/ fnins.2013.00159.

3. Alasmari W, Costello S, Correia J, et al. $\mathrm{Ca}^{2+}$ signals generated by CatSper and $\mathrm{Ca}^{2+}$ stores regulate different behaviour in human sperm. $\mathrm{J}$ Biol Chem 2013;288:6248-58. doi: 10.1074/jbc. M112.439356.

4. Strünker T, Goodwin N, Brenker C, et al. The CatSper channel mediates progesterone induced Ca2+ influx in human sperm. Nature 2011;471:3826. doi: 10.1038/nature09769.11.

5. Baker MA, Hetherington L, Reeves GM, et al. The mouse sperm proteome characterized via IPG strip prefractionation and LC-MS/MS identification. Proteomic 2008;8:1720-30. doi: 10.1002/pmic.200701020.

6. Sayme N, Dite L, Krebs T, et al. Positive effect of progesterone on motility and velocity of fresh, vitrified without permeable cryoprotectants and frozen with permeable cryoprotectans human spermatozoa. Andrologia 2018; e13133:1-7. doi: 10.1111/and.13133

7. Wiser A, Sachar S, Ghetler Y, et al. Assessment of sperm hyperactivated motility and acrosome reaction can discriminate the use of spermatozoa for conventional in vitro fertilisation or intracytoplasmic sperm injection: preliminary results. Andrologia 2013;46:313-5. doi: 10.1111/ and.12068.

8. Ramu S, Jeyendran RS. The hypo-osmotic swelling test for evaluation of sperm membrane integrity. In: Carrell D, Aston K, editors. Spermatogenesis. methods in molecular biology (methods and protocols). Totowa NJ: Humana Press;2013.p.21-5.

9. World Health Organization, Department of Reproductive Health and Research. WHO laboratory manual for the examination and processing of human semen. 5th ed. Geneva: World Health Organization, Department of Reproductive Health and Research;2010.
10. Perdrix A, Saidi R, Menard JF, et al. Relationship between conventional sperm parameters and motile sperm organelle morphology examination (MSOME). Int J Androl 2012;35:491-8. doi: 10.1111/j.1365-2605.2012.01249.x.

11. Cooper TG, Noonan E, von Eckardstein S, et al. World Health Organization reference values for human semen characteristics. Hum Reprod Update 2010;16:231-45. doi: 10.1093/humupd/ dmp048.

12. Lishko PV, Botchkina IL, Kirichok Y. Progesterone activates the principal $\mathrm{Ca} 2+$ channel of human sperm. Nature 2011;471:387-91. doi: 10.1038/ nature0976710.

13. Sumigama S, Mansell S, Miller M, et al. Progesterone accelerates the completion of sperm capacitation and activates CatSper channel in spermatozoa from the Rhesus macaque. Biol Reprod 2015;93:1-11. doi: 10.1095/ biolreprod.115.129783.

14. Rahman MS, Kwon WS, Pang MG. Calcium influx and male fertility in the context of the sperm proteome: an update. Biomed Res Int 2014;1-13. doi: 10.1155/2014/841615.

15. Agarwal A, Virk G, Ong C, et al. Effect of oxidative stress on male reproduction. World J Mens Health 2014;32:1-17. doi: 10.5534/wjmh.2014. 32.1.1.

16. Breznik BP, Kovacic B, Vlaisavljevic V. Are sperm DNA fragmentation, hyperactivation and hyaluronan-binding ability predictive for fertilization and embryo development in in vitro fertilization and intracytoplasmic sperm injection? Fertil Steril 2013;99:1233-41. doi: 10.10.16/j. fertnstert.2013.11.048.

17. Lodhi LA, Zubair M, Qureshi ZI, et al. Correlation between hypo-osmotic swelling test and various conventional semen evaluation parameters in fresh Nili Ravi buffalo and Sahiwal cow bull semen. Pak Vet J 2008;28:186-8.

18. Duru NK, Morshedi M, Schuffner A, et al. Semen treatment with progesterone and/or acetyl-Lcarnitine does not improve sperm motility or membrane damage after cryopreservationthawing. Fertil Steril 2000;74:715-20.

19. Smith JF, Syritsyna O, Fellous M, et al. Disruption of the pricipal, progesterone-activated sperm $\mathrm{Ca} 2+$ channel in a CatSper2-deficient infertile patient. Proc Natl Acad Sci USA 2013;110:6823-8.

20. Henning H, Ngo TT, Waberski D. Centrifugation stress reduces the responsiveness of spermatozoa to a capacitation stimulus in in vitroaged semen. Andrology 2015;3:834-42. doi: 10.1111/andr.12064. 
21. Mohammadi G, Mahdion H. Evaluation of membrane integrity of bull frozen-thawed sperm using water and hypo osmotic swelling test. Bas J VetRes 2017;16:131-43.
22. Youn JS, Cha SH, Park CW, et al. Predictive value of sperm motility characteristics assessed by computer assisted sperm analysis in intrauterine insemination with superovulation in couples with unexplained infertility. Clin Exp Reprod Med 2011. 38:47-52. doi: 10.5653/cerm.2011.38.1.47. 